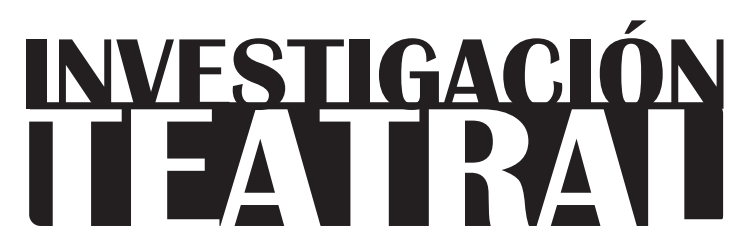

Revista de artes escénicas y performatividad

Vol. 12, Núm. 19

abril-septiembre 2021

Segunda época

ISSN impreso: $1665-8728$

ISSN electrónico: 2594-0953

Universidad Veracruzana

Reseña de puesta en escena

La alacena.

Documental miniatura

sobre María Izquierdo

\author{
Alicia Petrilli Vargas*
}

* Maestría en Artes Escénicas, Universidad Veracruzana, México.

e-mail: alis.petrilli@gmail.com

Recibido: 01 de diciembre de 2020

Aceptado: 09 de febrero de 2021

Doi: $10.25009 /$ it.v12i19.2660 
INVESTIGACIÓNTEATRAL

Revista de artes escénicas y performatividad

Vol. 12, Núm. 19

abril-septiembre 2021
La alacena. Documental miniatura

sobre María Izquierdo

Alicia Petrilli Vargas

\title{
La Alacena. Documental miniatura sobre María Izquierdo
}

El surrealismo era un grupo compuesto esencialmente por hombres que trataban a las mujeres como musas, eso era bastante humillante. Por eso no quiero que nadie me llame musa de nada. Prefiero que me traten como lo que soy: una artista.

Leonora Carrington

\begin{abstract}
I domingo 29 de noviembre del 2020, en el Foro Shakespeare, a las 19:30 horas, se
- estrenó la obra La Alacena. Documental miniatura sobre María Izquierdo, escrita 1 por Tanya Huntington, ${ }^{1}$ cuya producción fue realizada por Fortuna, Colectivo de Creación. ${ }^{2}$ Dicha obra cuenta con la dirección de Aurora Gómez Meza ${ }^{3}$ y las actuaciones
\end{abstract}

1 Doctorada en Literatura Latinoamericana por la University of Maryland. Editora de la revista digital Literal: Latin American Voices. Ha sido colaboradora en Tierra Adentro, Langosta Literaria y en https:// literalmagazine.com/ (Fundación para las letras mexicanas).

2 Fortuna, Colectivo de Creación "es una organización horizontal que busca generar espacios para la creación escénica con diversas técnicas y la difusión del conocimiento teórico-práctico" ("Fortuna, Colectivo de Creación").

3 Directora y productora escénica egresada de la Licenciatura en Literatura Dramática y Teatro de la UNAM. 
de Abigaíl Espíndola ${ }^{4}$ y Marysol Cordourier, ${ }^{5}$ quien fue responsable del proyecto escénico apoyado por la Beca Creadores Escénicos del Fondo Nacional para la Cultura y las Artes 2019. Este estreno se suma a las actividades de reapertura en los espacios teatrales de la Ciudad de México y, debido a las nuevas regularizaciones sanitarias, tuvo un cupo presencial limitado y la opción de acceso al espectáculo vía streaming, gracias a lo cual nos fue posible la "asistencia" a público en distintas partes del país.

La propuesta escénica de La Alacena... tiene como anécdota la vida y obra de María Izquierdo (1902-1955), reconocida pintora mexicana, quien alrededor de 1929 hizo su aparición en el ámbito de la pintura nacional dominado por figuras masculinas (Deffebach 14). En su artículo "Mujeres artistas en México", Rita Eder expone que las primeras consideraciones respecto al papel de las mujeres dentro de las artes en el país se hacen al final del siglo xx (252). Entre los documentos más significativos de aquella época que abordan esta problemática, Eder señala el artículo "La mujer artista", de Leopolda Gassó y Vidal, escrito en 1885, el cual subraya que los impedimentos en la educación y formación de las mujeres en el terreno de las artes detenían su desarrollo en dichos ámbitos $y$, de erradicarse estas diferencias, proliferarían las manifestaciones artísticas realizadas por las mismas:

Esperemos que desaparezcan estos errores, cuando la mujer, rotos los diques impuestos por la rutina en este como en otros ramos del saber, demuestren con sus obras la chispa divina que brilla en su frente, oculta hasta aquí por la preocupación y la ignorancia (Gassó y Vidal 222).

Casi cinco décadas después del artículo de Gassó y Vidal, la obra pictórica de María Izquierdo ha sido reconocida por la crítica debido al impresionante uso del color y la presencia de figuras femeninas como protagonistas, postura que se diferenciaba de las representaciones de los muralistas que colocaban a las mujeres como personajes secundarios dentro de sus obras (Franco citado en Deffebach 14). En palabras de Nancy Deffebach, "sus pinturas insisten, a veces sutilmente y otras abiertamente, en que al igual que sus colegas masculinos, las mujeres contribuyen significativamente al arte y a la sociedad mexicana" (34). En las pinturas de Izquierdo podemos observar mujeres valientes, diestras y fuertes, características que normalmente eran asociadas a imágenes masculinas plasmadas en los murales de su época (18). El proyecto La Alacena... retoma la historia

4 Actriz, titiritera y productora ejecutiva egresada del Colegio de Literatura Dramática y Teatro de la UNAM.

5 Actriz, titiritera, investigadora y docente. Maestra en Artes Escénicas por la Universidad Veracruzana y becaria Conacyt. 
de María Izquierdo para cuestionar qué ha cambiado respecto al rol de las mujeres en el arte en la actualidad.

La trama de la obra muestra la vida de Izquierdo desde los recuerdos de su infancia; su primer matrimonio antes de los 15 años y su divorcio; su entrada y su abrupta salida de la vida académica; su aparición en el mundo de la pintura y su relación con otros artistas, como Diego Rivera y Antonin Artaud; su incursión en las políticas de izquierda, así como su deserción de ellas; su relación con Rufino Tamayo; su llegada a Nueva York y la ruptura de esta relación; las noches de fiesta en compañía de sus congéneres; además, su nuevo matrimonio y la parálisis total de su brazo derecho hasta el momento de su muerte.

$\mathrm{Al}$ inicio de la obra se presenta el dispositivo escénico central: una alacena colorida y rebosante de diversos elementos, como los que aparecen en los cuadros de Izquierdo. Se encuentra dividida en réplicas de pinturas que se mueven de manera corrediza para revelar el rostro de las actrices animadoras. La cara de María Izquierdo es representada por una máscara plana dividida a la mitad de manera vertical; cada actriz lleva en su mano una de estas partes y, en diferentes momentos de la obra, las unen formando su rostro. La propuesta es un monólogo a dos voces, donde la pintora es representada por los gestos y acciones de las actrices, en coordinación con una narración grabada que resuena durante toda la obra, como si su origen se encontrara en el terreno de los muertos.

La alacena es un mecanismo convertible que se despliega transformando el espacio en distintos momentos de la función. La obra hace uso de diferentes técnicas: pop-up, teatro de papel, sombras, figuras planas, guiñol, medios digitales y, por supuesto, las actuaciones de Cordourier y Espíndola, que conforman una dupla más que talentosa. Se incluyen elementos de la cultura mexicana, como juguetes, marionetas de feria, papel picado y tocados de listones. En general, es una obra llena de colores, con una paleta similar a la de las pinturas de Izquierdo. La calidez que emana la plástica contrasta con los momentos conflictivos de la vida de la artista; a la vez, realzan el espíritu aguerrido y optimista, que es parte del discurso.

El uso de las sombras propicia un ambiente de ensueño, generando un efecto de inmersión en las memorias de la protagonista; los autorretratos son la evidencia de la agonía que deja en el lienzo, así como los temas de dulces, comidas y flores son los aromas que la rodearon en vida. La referencia a la Revolución mexicana se hace presente, pero no solo como acontecimiento histórico, sino también como espíritu y sentido, porque si es posible cambiar la realidad política del país, también lo es cambiar el arte, y dentro de ese nuevo arte se encontrarán las artistas.

En ese sentido, este proyecto es un maravilloso homenaje a aquellas mujeres que fueron ensombrecidas por figuras masculinas que se apoderaron del escenario artístico a lo largo de la historia. Al mismo tiempo, es un llamado a la sororidad a partir del reconocimiento 
INVESTIGACIÓNTEATRAL

Revista de artes escénicas y performatividad

Vol. 12, Núm. 19

abril-septiembre 2021
La alacena. Documental miniatura

sobre María Izquierdo

Alicia Petrilli Vargas

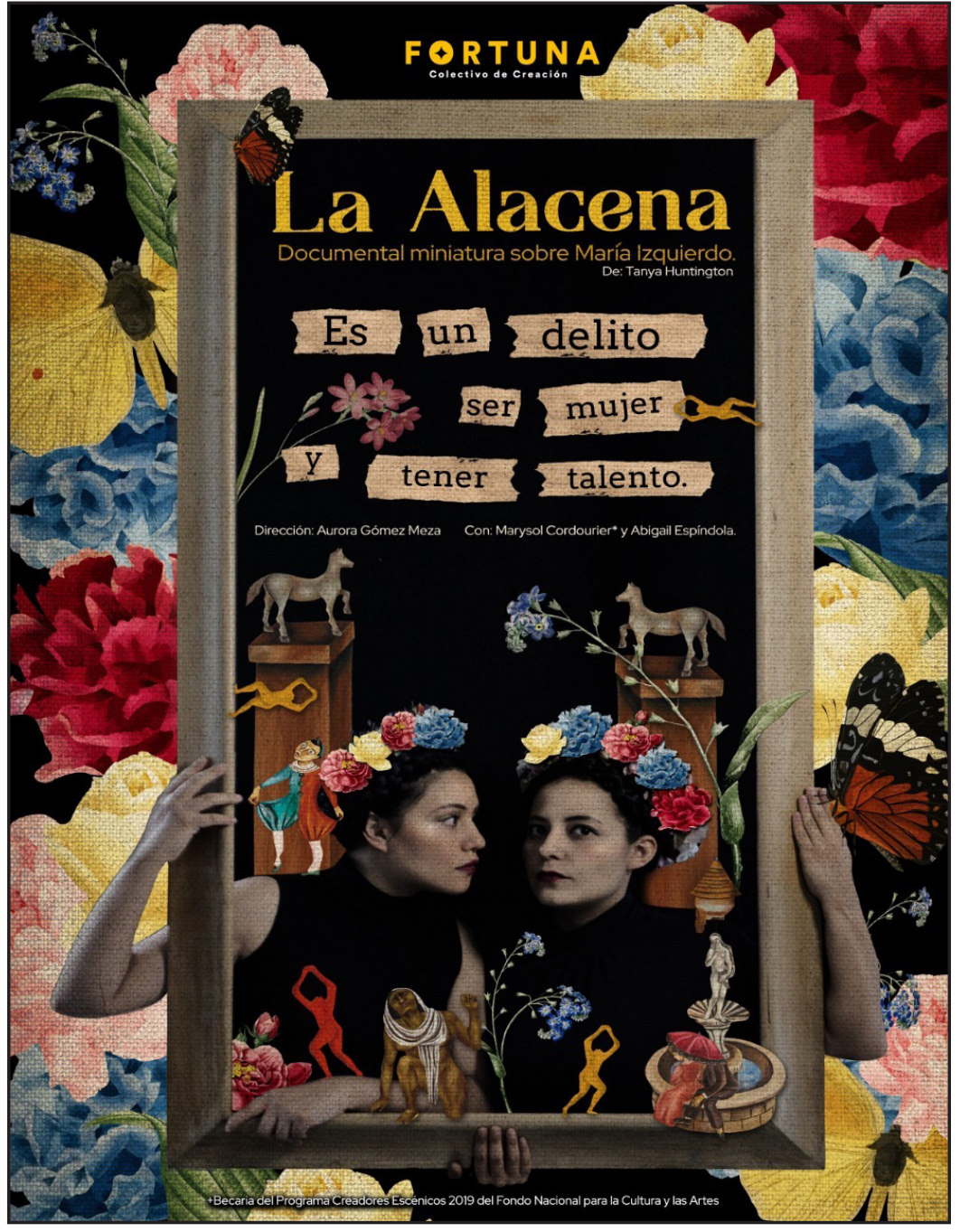

Imagen 1. Cartel de la obra La Alacena, documental miniatura sobre María Izquierdo. México, 2020. Diseño por Gabriela Gómez Meza. Fotografía de Mariana Xareni.

del hacer entre colegas y la incentivación de espacios de creación colaborativos entre artistas escénicas. Con dicha labor, las creadoras de La Alacena... plantean su cometido de reconfigurar en escena la famosa frase de Izquierdo: "es un delito ser mujer y tener talento" (ver Imagen 1$)^{6}$

$6 \quad$ La frase a la que refieren las creadoras es la misma que figura en el cartel: "es un delito ser mujer y tener talento", cuyo origen podría encontrarse en las memorias de la pintora respecto al inicio de su carrera: "era entonces un delito nacer mujer, y si la mujer tenía facultades artísticas, era mucho peor" (María Izquierdo citada en Deffebach 15). 
Respecto a las reacciones del público presente en la función no puedo decir mucho, aunque puedo hablar de mi experiencia como espectadora en línea. En primer lugar, admito que es bastante cómodo tener la posibilidad de asistir a una función de teatro que tiene lugar en la Ciudad de México, sin salir de mi casa en Xalapa, Veracruz. Por otra parte, ciertos acercamientos de la cámara me permitieron apreciar diferentes detalles que de otra manera podían haber pasado desapercibidos, además de que el lugar privilegiado de la cámara suele encontrarse libre de obstrucciones visuales.

Sin embargo, no está de más recordar que nada sustituye la presencia física en un teatro y que el estado de la red de internet en casa afecta la calidad del video. Tener una conexión deficiente puede llevar a la interrupción de la transmisión y perder buena parte de la obra, ya que no permanece grabada en una plataforma. Por fortuna, esto me ocurrió en una única ocasión y solo un par de segundos. Fuera de ese problema, la obra es disfrutable, el texto es ágil y con buen ritmo. Quizá puedan llegar a hacer falta algunas pausas o silencios para terminar de digerir ciertos momentos, pero la riqueza del juego entre las actrices dinamiza todas las situaciones.

La Alacena es una obra bella, tanto plástica como discursivamente, aguerrida como su protagonista; muestra de ello es que ha logrado persistir pese a la contingencia de salud por la que atravesamos. Es un logro digno de aplaudir y una celebración para los que deseamos la reapertura de los teatros. Espero podamos presenciar próximas funciones, y ya sea que la veamos de manera presencial o en línea, será sin duda una maravilla.

\section{Ficha técnica}

Nombre de la obra: La Alacena. Documental miniatura sobre María Izquierdo. Compañía: Fortuna, Colectivo de Creación. Fecha y lugar de estreno: 29 de noviembre del 2020, Ciudad de México, Foro Shakespeare. Dramaturgia: Tanya Huntington.

Dirección: Aurora Gómez M. Asistencia de dirección: Erika Franco.

Diseño de arte y desarrollo de medios digitales: Gabriela Gómez Meza.

Diseño de vestuario: Pilar Boliver.

Diseño y realización de escenografía: Pablo Cueto.

Musicalización: Luis Angel Pimienta Rodríguez.

Diseño y construcción del Pop-up: Ainé Martelli.

Diseño y realización del guiñol: Rolando García.

Reparto: Marysol Cordourier y Abigaíl Espíndola. 


\section{Fuentes consultadas}

Deffebach, Nancy. "María Izquierdo: arte puro y mexicanidad". Revista Co-herencia, vol. 15, núm. 29, 2018, pp. 13-36, https://www.scielo.org.co/pdf/cohe/v15n29/1794-5887cohe-15-29-00013.pdf, consultado el 30 de noviembre del 2020.

Eder, Rita. "Las Mujeres Artistas en México". Anales Del Instituto De Investigaciones Estéticas, vol. 13, núm. 50, tomo 2, 1982, pp. 251-60, http://www.analesiie.unam. $\mathrm{mx} /$ index.php/analesiie/article/view/1144/1131, consultado el 20 de enero de 2021.

"Fortuna, Colectivo de Creación". Facebook. https://www.facebook.com/Fortuna-Colectivo-de-Creaci\%C3\%B3n-105739481239427/about, consultado el 30 de noviembre del 2020.

"Fortuna, Colectivo de Creación". Carpeta del proyecto: La Alacena, documental miniatura de María Izquierdo. Archivo personal del colectivo, consultada el 30 de noviembre del 2020.

Gassó y Vidal, Leopolda. "La mujer artista. III". El Álbum de la mujer. Ilustración hispano-mexicana. Año 3, tomo 5, núm. 23, domingo 13 de diciembre de 1885.

La Alacena, documental miniatura de María Izquierdo, de Tanya Huntington. Dirigida por Aurora Gómez Meza, Fortuna, Colectivo de Creación, 29 de noviembre del 2020, Foro Shakespeare, Ciudad de México, transmisión en vivo. 